\title{
The Virtuous Ensemble: Socratic Harmony and Psychological Authenticity
}

\author{
Paul Carron \\ and \\ Anne-Marie Schultz \\ Baylor University
}

\section{Introduction}

We discuss two models of virtue cultivation that are present throughout the Republic: the self-mastery model and the harmony model. Schultz (2013) discusses them at length in her recent book, Plato's Socrates as Narrator: A Philosophical Muse. We bring this Socratic distinction into conversation with two modes of intentional regulational strategies articulated by James J. Gross. These strategies are expressive suppression and cognitive reappraisal. We argue that that the Socratic distinction helps us see the value in cognitive reappraisal and that the contemporary neurological research supports the wide range of attitudes toward the value of emotional experience that mirror those found in the Republic.

First, we outline the self-mastery and the harmony model. Second, we discuss Gross's two models and suggest how the Socratic models map very nicely onto them. We argue that Socrates' insight about the instability of the self-mastery model buttressed by contemporary empirical research confirms that we ought to prefer the cognitive reappraisal model because of the authenticity and integrity displayed in those who practice it. Finally, we argue that contemporary research upholds Plato's nuanced understanding of self-comportment. This provides an alternative interpretation to the traditional view of virtue cultivation in the Republic which calls Socratic intellectualism into question. Moreover, we argue that - contrary to the traditional view-Plato articulates a positive role for the emotions that is reinforced by contemporary empirical research.

\section{The Self-Mastery Model and the Harmony Model}

In this section, we discuss a provocative argument from the recent book, Plato's Socrates as Narrator. In the chapter on the Republic Schultz argues against the intellectualist view of Socrates in part by demonstrating that there are two models of self-comportment at work in the Republic. Here we will summarize her findings. According to Schultz, the traditional interpretation of self-comportment - the self-mastery model-ac- 
cords well with Socratic intellectualism, which "seems to identify virtue with knowledge and therefore appears to consider the affective side of our nature irrelevant to our virtue, to what counts as a good life." (Nehamas, 1992, p. 280). The self-mastery model of virtue requires that the logistikon (the rational part of the soul), rule over the epithumetikon (the appetitive part) with the help of the thumetikon (the spirited part). In this model, the appetites and emotions hinder our ability to be virtuous. The logistikon must therefore master these strong influences and work to diminish them as much as possible. This model depends upon the tripartite conception of the soul found in Book IV of the Republic. Though Socrates qualifies his confidence in their ability to "get a precise grasp of it on the basis of procedures such as we're now using in argument" (435d), nonetheless, he proceeds with his analysis (437b). Socrates first discusses the epithumetikon, the lowest part of the soul. Its scope is "being thirsty and hungry, and generally the desires, and further, willing and wanting" (437b). It is the seat of our appetites, desires, and the emotions associated with satisfying our appetites and desires. Appetites, desires and emotions are different mental states with different directions of fit, so it might seem odd that Socrates lumps them together. However, what they have in common is that they all tend to be more automatic actions rather than conscious, deliberate actions. Furthermore, these more automatic processes can easily overwhelm the agent's ability to control them.

After Socrates describes the epithumetikon, he discusses the logistikon. This part of the soul is responsible for our ability to reason and reflect. It participates in all pursuits related to learning and acquiring knowledge. It contemplates and philosophizes: the logistikon is the seat of the highest human activity. Socrates initially presents the logistikon's purpose as largely negative and constraining. Socrates asks Glaucon, "if ever something draws it [the epithumetikon] back when it's thirsting, wouldn't that be something different in it from that which thirsts and leads it like a beast to drink?" (439b). Socrates asks again, "isn't there something in their soul bidding them to drink and something forbidding them to do so, something different that masters that which bids?" (439c). The third part of the soul contains spirit [thumos]. Thumos is that "with which we are spirited" (439c). It produces ferocity and courage when properly balanced, but can easily be drawn out of balance and contribute to cruel and harsh behaviors. Given the constraints of this paper, we use the logistikon and epithumetikon as the modes of comparison to contemporary research. We feel justified in this emphasis because Socrates expresses some doubt as to whether it is really a third distinct part of the soul. 


\section{Socratic Harmony and Psychological Authenticity}

In sum, the self-mastery model prioritizes reason as the means by which we become good and dismisses the role the other parts of the soul can play in the process of becoming good. Under this view, the appetites present distracting and, at times, even dangerous obstacles that we must overcome in our pursuit of justice in the soul. Socrates allows for some positive therapeutic function for certain forms of poetry in early education. It seems there, at least, the proper formation of the lowest part does allow it to play some role in becoming good, or welcoming the good when one sees it (401d-402a).

Schultz argues that the self-mastery model is not the only model present in the Republic: in fact, Socrates employs images of harmony to describe the nature of justice in both the city and the soul. This view has vast implications for reading Plato and understanding his view of the emotions and virtue cultivation which she explores in Plato's Socrates as Narrator. Here we focus on explicating the harmony model and demonstrating its affinity with contemporary models of emotion regulation. In the Republic, Socrates refutes Thrasymachus' view that justice is nothing other than the interest of the stronger. He remarks that justice produces "unanimity and friendship" amongst people (351d). In a just city, people live in harmony with each other. One faction of the population does not rule over another faction. Another instance of the harmony model on the level of the city occurs after Socrates presents the image of the sun, the line, and the cave. Socrates explains how they will ensure the establishment of justice in the city by "compelling" those with the best natures to rule (519d). Glaucon objects: "Are we to do them an injustice, and make them live a worse life when a better is possible for them?" (519e). Socrates employs a harmony metaphor to address Glaucon's concern. They are concerned with "the city as a whole, harmoniously uniting citizens by persuasion and necessity, causing them to share with each other the benefit each is able to bring to the commonwealth" (520a). A just city functions according to the principles of harmony, not the principles of mastery. Socrates uses metaphors of harmony to describe the structure of the cosmos as well (531d and 617b). A just soul mirrors the harmonious ordering of the cosmos. Socrates also employs metaphors of disharmony when discussing injustice in the city. In his initial exchange with Thrasymachus, Socrates notes that injustice "produces factions, hatreds, and quarrels" (351d). The citizens cannot live in harmony with each other. They fight against each other instead of working for the good of the city together (547a).

The harmony model is distinct from the self-mastery model in several ways. First, the harmony model allows the epithumetikon to have a voice. It provides necessary notes on the scale of internal justice (443d). The har- 
mony model emphasizes the role of the appetites and the emotions in the well-ordered soul (441a). To see how harmony comes about in the soul, consider the metaphor of a vocal ensemble. A trio has a leader, a person that makes final decisions about the composition of each piece. However, in a well-composed trio all three voices are always in harmony, but the lead voice is not always singing melody. Different members will take the melody at different points depending on what is appropriate for the piece. Analogously, in a well-ordered soul all three parts are always in harmony. However, like the trio, one part-the logistikon - makes the final call on which part is emphasized at what time. True harmony of soul requires that the logistikon incorporates the thumetikon and the epithumetikon.

\section{Intentional Regulatory Strategies:}

\section{Expressive Suppression and Cognitive Reappraisal}

Simply put, in these two models of self-comportment, Socrates articulates two versions of what is now called an intentional regulatory strategy. ${ }^{1}$ Engaging in intentional regulatory strategies (whether instantaneous or over extended periods of time) allows the individual to have different emotions and perform different actions. Furthermore, these strategies change the neurological structure and activity in the brain. There is a feedback loop involved in this process. Intentional regulatory strategies change neurological activity, and over time these changes can become permanent, allowing for the agent to more easily engage in the regulatory strategy. Research on the effects of meditation on the brain is particularly relevant here.

Recent studies in psychology and neurobiology support the view that human beings can intentionally influence both their mental states and their neurological activity. Disentangling neurological activity from mental states is a philosophically vexing issue. On the one hand, it seems (both philosophically and neurobiologically) that there cannot be a mental state that does not have a corresponding neural process. However, some of the recent research points to a kind of agential metacognitive control over one's neurological activity that is probably rooted in the prefrontal cortex, yet hard to identify empirically since the locus of activity can be in the amygdala and the PFC depending on what the agent is trying to accomplish (i.e. either suppress or allow an emotion). The question is which area of the brain determines which area of the brain is in control? This has led researchers such as Mario Beauregard, Jeffrey M. Schwartz and Gross to posit a metacognitive or executive mental feature that emerges out of neurological activity but is not fully reducible to it (Schwartz calls this "emergent materialism"). Psychologist James J. Gross focuses on 


\section{Socratic Harmony and Psychological Authenticity}

different cognitive strategies that humans can engage in to influence what emotions they have, how they express them, and what behaviors follow those emotions. Gross identifies five different points in the emotion generation sequence. Four of these strategies are antecedent-focused-they take place before the emotion has been generated - and one is responsefocused-it takes place after the emotion is generated. For the purposes of this paper, we focus on just two strategies, one antecedent-focused and one response-focused. We argue that these two emotional regulation strategies map onto the two forms of Socratic self-comportment.

The response-focused regulation strategy is expressive suppression, which we believe has strong similarities to the Socratic self-mastery model. Expressive suppression involves inhibiting ongoing emotion-expressive behavior. In this strategy, the agent "attempts to influence emotions response tendencies once they already have been elicited," for instance, by attempting to suppress an emotional response that the agent is currently having (Gross, 2002, p. 283). This strategy is utilized in situations where the agent is already experiencing an emotional response, and wishes to modulate that response ex post facto. Gross and Mario Beauregard have conducted experiments that examine this strategy. In one study, Gross had three groups view film clips picked to elicit negative emotions in the subjects. One group was instructed to utilize a suppression strategy (response focused), the second group was instructed to utilize a reappraisal strategy (antecedent focused), and the control group was instructed simply to view the clip. Gross concluded, "suppression (when compared to reappraisal and control groups) decreased the behavioral expression of negative emotion but not the subjective experience" (2004, p. 1306). The subjects still reported feeling sad, but did not display any behaviors typically associated with sadness. Furthermore, agents who engaged in suppression strategies also "showed signs of greater physiological activation (in cardiovascular and electrodermal systems) than participants who simply watched" (2004, p. 1306). In other words, suppression keeps the internal emotion from generating correlated behavior, but it does not keep the agent from experiencing the internal aspect of the emotion. Gross notes that one of the main limitations of this experiment is the lack of a longitudinal element. For instance, one might wonder if the affects would be different if the agent developed a habit of suppression where it becomes much easier to suppress over time. Hopefully further research will shed some empirical light on this question. Moreover, suppressing the emotion takes more effort and energy than reappraisal, making it the more taxing emotion regulation strategy over the long-term.

Another example of a suppression strategy is seen in a study conducted 
by Beauregard et al. that performed fMRIs on men while watching erotic film clips. In the sexual arousal condition, they were told to react normally to these stimuli, not to suppress arousal. In the suppression condition, they were told to "suppress any feelings elicited by the erotic film excerpts" by becoming "a detached observer" (2007, p. 220). This is a response-based modulation strategy because the agent cannot avoid the emotionally laden situation, and cannot stop the external stimulus from starting the emotiongeneration sequence. ${ }^{2}$ Once the emotion starts, the agent uses a cognitive strategy to view the situation from a different perspective and keep the emotion from generating "emotion-expressive behavior." The differences between the two conditions were not subtle. Neurologically, the sexual arousal condition produced activity in mainly older parts of the brain (the limbic system and amygdala for instance) associated with automatic responses. The suppression condition however activated cortical activity, parts of the brain associated with decision-making and conscious goaldirected activity. Beauregard and his colleagues concluded that this difference provides strong evidence for the view that "emotional self-regulation depends on a neural circuit in which the prefrontal cortical areas mediate the cognitive modulation of emotional responses generated at the subcortical level (2007, p. 220). In other words, self-mastery is possible (at least momentarily) and changes brain activity.

The antecedent-focused regulation strategy is cognitive reappraisal, which we believe has strong similarities to the Socratic harmony model of self-comportment. Gross describes the strategy of cognitive reappraisal as an "antecedent form of cognitive change that involves construing a potentially emotion-eliciting situation in a way that changes its emotional impact" (2004, p. 1304). Unlike response-based strategies such as suppression, cognitive reappraisal comes early in the emotion-generation sequence and influences whether or not particular emotion response tendencies are triggered in the first place. When utilizing antecedent strategies the agent is not fighting an emotion that has already been triggered and trying to keep that emotion from leading to correlated behaviors. Rather the agent employs strategies that can prevent the onset of negative emotions (or emotions that might lead to unwanted behaviors).

Several examples from recent research illuminate the nature and benefits of antecedent-focused strategies such as cognitive reappraisal. For instance, Jeffrey M. Schwartz's (1999) research on cognitive-behavioral OCD therapy is an example of a long-term antecedent-focused strategy that includes cognitive reappraisal as well as other of Gross's antecedentfocused strategies. Schwartz and other researchers discovered that OCD stems from malfunctioning neural circuitry in the brain, but because of the 


\section{Socratic Harmony and Psychological Authenticity}

brain's neuroplasticity, the agent can correct this malfunctioning neural circuitry. To facilitate this neural change, Schwartz developed a four-step cognitive-behavioral method (1999, p. 122). The first step is for the agent to relabel the obsessive thoughts by recognizing that those thoughts and urges are a result of OCD. The second step is to "reattribute" by realizing that the intensity and intrusiveness of the thought or urge is caused by a chemical imbalance in the brain that causes the OCD. The third step is to "refocus" by turning one's attention to something else besides the obsessive thoughts by for instance performing another behavior. The last step is to "revalue" the thoughts and tell oneself that the thoughts the OCD cause should not be taken at face value and are not significant. Numerous patients who engaged in this nine-week program experienced both objective and subjective change. They reported significant reduction in their OCD behavior and their brain activity was significantly different. Schwartz notes that "What this accomplishes is a change in perspective away from automatic responses (exactly the sort of activity the basal ganglia is wired by many millennia of evolution to perform)... and toward a more precise, considered, and consciously goal-directed interpretation of the present moment's experience-which is, of course, a much more cortically directed activity" (1999, p. 127). Extended regulation strategies can change neural activity, the generation of emotions and impulses, and the associated behaviors.

\section{Some Concluding Remarks}

When comparing the two Socratic models of self-comportment-selfmastery and harmony - with these two views of emotion regulation-expressive suppression and cognitive reappraisal-a number of interesting elements emerge. Consider the similarities between the Socratic selfmastery model and the response-based suppression strategy. Gross notes that one very old and pervasive view of the emotions is that they are "[i] rrational forces that unleash destructive thoughts and impulses..." (2004, p. 1306). Socrates' self-mastery model adopts a similar view, seeing emotions and appetites as strong influences that must be mastered or else they hinder the agent's ability to be virtuous. Socrates presents the different parts of the soul (which correlate nicely with parts of the brain - the prefrontal cortex and the limbic system/amygdala) as constantly in conflict with each other and that the emotions "set themselves up as rulers in us when they ought to be ruled" (606d). Emotions and appetites constantly bombard the agent with urges that conflict with the agent's true, rational nature, and must be battled and mastered. The logistikon must continually subdue the epithumetikon for the well-being of the soul, draining the 
agent's cognitive energy and producing a sense of inauthenticity in the agent. Gross makes the former point about energy when comparing the suppression and reappraisal models. He notes, "[p]hysiologically, participants who suppressed showed signs of greater physiological activation (in cardiovascular and electrodermal systems) than participants who simply watched (or reappraised)" (2004, p. 1306). Not only is the struggle constant, but also the strategy takes more energy in addition to other negative repercussions. Gross remarks "reappraisal decreased both the experience and the behavioral expression of negative emotion without any increase in physiological activation" (2004, p. 1306). In other words, whereas agents who suppressed their emotions managed to decrease the associated behaviors, they still subjectively experienced the emotion and expended more energy in the process. Agents who reappraise not only decrease both the associated behavior and subjective experience of the emotion, but also spend less energy doing so.

Another consequential difference between the two strategies appears in the research. Individuals who chronically use suppression "are keenly aware of their lack of authenticity, and they admit to deceiving others about their true inner feelings, attitudes, and beliefs. They do so, they report, because they are concerned about not being accepted by others..." (2004, p. 1313) Gross defines authenticity as the "extent to which individuals behave in ways that are congruent with their own inner feelings, attitudes, and beliefs, rather than engaging in knowingly false self-presentations" (2004, p. 1313). Furthermore “...suppression was related to inauthenticity but reappraisal was not” (2004, p. 1313). Regularly utilizing suppression methods leaves the agent keenly aware of the discrepancy between his/ her inner feelings and outward expression. In Socratic terms, suppression creates disharmony in the soul. When describing the harmony model of self-comportment, Socrates states that the just person "doesn't let each part in him mind other people's business or the three classes in the soul meddle with each other, but really sets his own house in good order and rules himself. He arranges himself, becomes his own friend, and harmonizes the three parts, exactly like three notes in a harmonic scale, lowest, highest and middle" (443d). The just person's soul is in harmony with itself. The different aspects of the self do not struggle for dominance; the logistikon makes the final call, but the other aspects are emphasized when appropriate. Sometimes an emotional response is appropriate to the situation, sometimes not. In those moments the logistikon needs to employ an antecedent-focused strategy such as reappraisal to keep itself from battling itself, to retain authentic integrity.

One final point of comparison: surely Socrates would not have spent 


\section{Socratic Harmony and Psychological Authenticity}

so much time explaining the self-mastery model if he thought it was only negative. Gross (2004, p. 1312) observes that most people utilize both response-based and antecedent-based strategies; indeed, it seems to follow from his research that both are necessary for psychological and social well-being. They are not mutually exclusive. Socrates knew that both strategies were necessary and not exclusive. However, someone who engages primarily in response-based strategies will be depleted of important cognitive resources and energy and will have a deep sense of inauthenticity. Long before this contemporary research, Socrates was aware of the range of emotional experiences and the necessity of different strategies for different experiences and situations. Furthermore, Socrates seemed quite aware that what we now call Expressive Suppression as the primary mode of emotional regulation was detrimental to a productive sense of self; that is why he offers the harmony model as a check against the self- mastery model as the primary mode of virtue cultivation.

\section{Notes}

1 By Socrates, we mean the character in the Platonic dialogues, not the historical Socrates. Whether or not Plato espoused the views that Socrates articulates is a deeply vexed question and one we will not address here.

2 This may not be the case for someone who has spent much time in meditation and contemplation (like a monk for instance), but these were all "average Joes" who would almost inevitably be affected by the subject matter.

\section{Works Cited}

Beauregard, M. (2007) Mind does Really Matter: Evidence from Neuroimaging Studies of Emotional Self-Regulation, Psychotherapy, and Placebo Effect. Progress in Neurobiology 81(4): 218-236.

Gross, James J. (2002) Emotion Regulation: Affective, Cognitive, and Social Consequences. Psychophysiology 39(3): 281-291.

John, Oliver P. and James J. Gross. (2004) Healthy and Unhealthy Emotion Regulation: Personality Processes, Individual Differences, and Life Span Development. Journal of Personality 72(6): 1301-33.

Nehamas, A. (1992) What Did Socrates Teach and to Whom Did He Teach It? The Review of Metaphysics 46(2): 279-306.

Plato. (1997) Complete Works. John M. Cooper and D. S. Hutchinson (eds.). Indianapolis, IN: Hackett.

Schultz, A. M. (2013) Plato's Socrates as Narrator: A Philosophical Muse. Lanham: Lexington Press. 


\section{Paul Carron and Anne-Marie Schultz}

Schwartz, Jeffrey M. (1999) A Role for Volition and Attention in the Generation of New Brain Circuitry: Toward a Neurobiology of Mental Force. Journal of Consciousness Studies 6(8): 115-72. 